\title{
Canadian Pandemic Influenza Preparedness: Communications strategy
}

\author{
B Henry ${ }^{1,2}$ on behalf of the Canadian Pandemic Influenza Preparedness (CPIP) Task Group*
}

\section{Abstract}

When faced with uncertainty and unpredictability, early and transparent communication during a pandemic is critical to build trust and to ensure the credibility of public health advice. The responsibility for communicating with Canadians during a pandemic is shared by federal, provincial, territorial and local governments. A common plan is needed to ensure consistent, coordinated and appropriate communication. Canada's diversity in terms of its size, geography, languages and culture also requires a multifaceted approach so that the right message is delivered at the right time to the right person in the right format.

The Communications and Stakeholder Liaison Annex is a recently updated communication strategy in the Canadian Pandemic Influenza Preparedness: Planning Guidance for the Health Sector (CPIP). The Annex emphasizes the importance of communicating with both the public and key stakeholders (e.g., health care providers, professional organizations and policymakers) before, during and after a pandemic. This strategy is grounded in several communications guiding principles: putting the health of Canadians first; providing timely and sound information; communicating in a coordinated fashion from across all levels of government; protecting confidentiality; and monitoring and adapting to the public's perception of risk. The Annex outlines a risk communications approach, proposes triggers for action based on pandemics of varying impact, and includes a Communication Protocol that will be used countrywide in the event of a pandemic.

\section{Affiliations}

${ }^{1}$ CPIP Task Group Chair

2 Office of the Provincial Health Officer, Victoria, BC

*Correspondence: phac.cpip. tg.secretariat-gt.pcp.aspc@canada. ca

Suggested citation: Henry B on behalf of the Canadian Pandemic Influenza Preparedness (CPIP) Task Group. Canadian Pandemic Influenza Preparedness: Communications strategy. Can Commun Dis Rep. 2018;44(5): 106-9. https://doi.org/10.14745/ccdr.v44i05a03

Key words: Influenza pandemic, communication strategy, risk perception, risk communication, emergency protocol

\section{Introduction}

During a pandemic, timely and transparent communication is critical in building public trust in the capacity of officials to manage the pandemic and to protect Canadians. At each stage of the pandemic, providing accurate, credible and timely information-through the right message, delivered at the right time by the right person to the right audience-can help protect the public's health, save lives and minimize social and economic disruption.

The "Communications and Stakeholder Liaison Annex" (1) is a recently updated communication strategy in the Canadian Pandemic Influenza Preparedness: Planning Guidance for the Health Sector (CPIP) (2). The primary focus of this Annex is federal, provincial and territorial (FPT) communication with the public, but it also recognizes the importance of communication with key stakeholders-health care providers, professional organizations and policymakers. The Annex has been updated based on experience gained during the 2009 H1N1 pandemic. That pandemic underscored the importance of clear, frequent and coordinated outreach to the public and key stakeholders and the need to plan for pandemics of varying impact.
This updated Annex uses a flexible and scalable approach to planning and includes best practices in risk communications. It integrates a broad range of communication methods such as social marketing, social media and stakeholder consultation. It outlines the roles and responsibilities of FPT governments in communications during a pandemic and the mechanisms through which key messages are coordinated, such as through established networks and nongovernmental organizations. The Annex is consistent with the concepts in the main body of the CPIP; it frames communications approaches using the guiding principles of ethics, collaboration, proportionality and evidenceinformed decision-making.

\section{Objectives}

In a pandemic, risk communication objectives are to inform and to engage Canadians, and the organizations that represent them, about the risks posed by the pandemic so that people can take appropriate actions. This is done by conveying the relevant information in formats that are accessible and tailored to audience needs (e.g., in different languages, culturally sensitive) 
and provided by and through multiple platforms (e.g. delivery by local leaders such as community elders or town mayors) and by coordinating communications through a clear focal point (e.g. from the Chief Medical Officer of Health). Established FPT networks are accessed to ensure consistency in messaging and share best practices and adjust approaches as necessary during the pandemic.

This article summarizes the recently updated Communication and Stakeholder Liaison Annex of the CPIP (1), and is part of a series outlining Canada's approach to influenza pandemic preparedness (3-6).

\section{Canadian context}

The Pan-Canadian Public Health Network (PHN) is the means by which a communications response is coordinated during a pandemic. The PHN is governed by a 17-member council of FPT government officials, including the Chief Public Health Officer and senior government officials from all provinces/territories who are responsible for public health. The PHN includes an intergovernmental communications group that provides risk communications and social marketing advice and support during a pandemic, facilitating cross-jurisdictional coordination and information-sharing among Canadian public health leaders.

Due to Canada's size and geographic population distribution, it is likely that a pandemic will affect different regions at different times and with varying severity, so messaging needs to explain the current situation in the global, national and regional context and address misinformation that may be circulating.

The Public Health Agency of Canada (PHAC) provides a focal point for national communications on public health issues. The PHAC collaborates with international organizations (e.g., the World Health Organization, the Global Health Security Action Group and the trilateral working group involved with the North American Plan for Animal and Pandemic Influenza [NAPAPI]), and coordinates with other federal departments to communicate health advice to Canadians, for example, on what precautions to take when travelling and how to prevent disease and injury.

The provinces/territories are the principal source of communications to the public and key stakeholders such as municipal and regional health authorities or provincial and territorial agencies or partners, within their jurisdictions. The $\mathrm{PHAC}$ and the provinces/territories coordinate their efforts and approaches through the PHN Communications Group.

In addition, the Annex identifies the importance of aligning communication strategies with trends in how Canadians access and use health information. Planners need to accommodate the fact that some Canadians have no or limited or unreliable Internet access. In addition, some populations may benefit from receiving information in different formats and languages, for example, those with hearing or visual impairments or low literacy, recent immigrants, or people experiencing homelessness. Several strategies can be used to reach Canadians: direct outreach to communities, traditional media (e.g., newspapers, telephone, radio and television), and new media trends and creative approaches (e.g., engaging outreach workers, social media) in addition to online media outlets.

\section{Key elements of the communication approach}

The Communications and Stakeholder Liaison Annex includes a joint FPT protocol for emerging public health events. This protocol identifies six guiding principles for pan-Canadian communications that can and should be applied during a pandemic context (see text box).

\section{Guiding principles for communications during an influenza} pandemic

1. Put the health of Canadians first. Ensure Canadians have the information they need to protect themselves and others.

2. Provide information that is informed by the latest available evidence. Information provided to the public must be as accurate as possible as it may be crucial to address misinformation and to enable people to protect themselves.

3. Provide information in a timely manner. Timely communication can prevent the spread of infections, thus reducing the severity and duration of outbreaks and saving lives.

4. Communicate in a coordinated fashion. It is important that all governments and partners who share responsibilities for public health align their efforts and ensure that the information they are providing to the public is consistent and appropriate.

5. Protect patient confidentiality. The patient's right to privacy should inform communications messaging. In turn, this messaging should comply with FPT protections, which balance public health interests with the rights of the individual patient.

6. Consider public perception of risk. Monitoring public perception, information needs and concerns is an important role in the pandemic response as public risk perception is the strongest indicator of willingness to change behaviour during a public health event.

\section{Risk perception}

The Annex highlights the importance of the public's risk perception, which is defined as "a subjective judgement that people make about the risks and benefits associated with an event or alternative courses of action" (1). Uncertainty during a pandemic can be accompanied by a high demand for information, increased feelings of fear and anxiety, rapid spread of misinformation, and speculation.

Risk communications theory suggests that an individual's initial perception of risk is formed early during a pandemic, based on the information available, and that it is filtered through personal beliefs, education and values (7). Moreover, once internalized, these perceptions are difficult to alter. Therefore, transparent, open and early communication with the public and stakeholders on what is known and what remains unknown (including actions being taken to gain further understanding) is critical. The annex emphasizes that public health authorities and trusted sources (e.g., nurses, doctors, pharmacists, community leaders, elders) not only influence early behaviours, but also establish the presence of a source of expert guidance and advice to help Canadians better understand the risks.

Social media plays an increasingly important role in how the public perceives risk. During a pandemic, many Canadians are likely to seek information on the outbreak through social media 
channels (e.g., Facebook, Twitter). In this context, stakeholders can play an important role in influencing public perception of pandemic risk-either by correcting misinformation or by recirculating accurate and consistent messages. The recommended communication strategies take into account this new reality, both in terms of how information is disseminated and how social media is monitored. Strategies must be in place to counter the risks of misinformation ("fake news"). Social media, while not the creator of fake news, provide a widespread platform through which opinion or misinformation can be convincingly and quickly disseminated as fact. Credible information must be presented early and repeated often by trusted sources.

\section{Scalability}

In the 2009 pandemic, there was considerable variation in pandemic wave activity in terms of timing and intensityaround the world, across Canada and within the provinces and territories. This made it clear that a flexible and scalable planning approach was necessary. As outlined in the CPIP, the response to a pandemic needs to be appropriate to the local situation, with relevant actions applied at the provincial/territorial or regional/local level, as the situation requires.

The CPIP outlines four planning scenarios that describe pandemic impacts from low to high based on virus transmission and clinical severity. Table 1 highlights these planning scenarios and their implications for risk communications.

\section{Ongoing evaluation}

There is a need for systematic evaluation of the overall communications response at three key stages of the pandemic:

- Continuously: To enable jurisdictions to adapt their plans to evolving circumstances and to share insights with their FPT counterparts to help to ensure a seamless and mutually reinforcing pan-Canadian communications response during the outbreak.

- $\quad$ Between the first and second wave: Recognizing that previous pandemics in North America have exhibited two waves, during the "pause," jurisdictions should reflect on their individual and collective response to the first wave of the outbreak and adjust their activities accordingly in advance of a potential second wave.

- After the pandemic: Evaluations will vary by jurisdiction, depending on the impact of the pandemic and the scope and scale of the communications response. Jurisdictions are encouraged to evaluate the effectiveness of their communications materials with their FPT counterparts.

To assist in these efforts, the Annex includes a list of performance indicators for both communication processes and outcomes that can be applied to evaluate the effectiveness of communications approaches and tools.

\section{Integration of communication strategies with other CPIP components}

Effective messaging and using a risk communications approach are inherent in every element of a pandemic response. Examples
Table 1: Implications and recommended adjustments to the communications response for pandemics of varying impact

\begin{tabular}{|c|c|c|}
\hline \multirow[t]{2}{*}{ Transmission } & \multicolumn{2}{|c|}{ Clinical severity } \\
\hline & LOW & $\mathrm{HIGH}$ \\
\hline HIGH & $\begin{array}{l}\text { Scenario B (moderate } \\
\text { impact): An influenza virus } \\
\text { with high transmissibility and } \\
\text { low virulence } \\
\text { - Anticipate that higher } \\
\text { transmissibility will } \\
\text { heighten public concern } \\
\text { and increase demand for } \\
\text { antivirals or pandemic } \\
\text { vaccine } \\
\text { - Develop communications } \\
\text { to reinforce public health } \\
\text { measures (vaccination, } \\
\text { hand hygiene) and caring } \\
\text { for the ill } \\
\text { - Incorporate workplace } \\
\text { wellness messages into } \\
\text { internal communications } \\
\text { (e.g., employee } \\
\text { newsletters) } \\
\text { - Implement marketing } \\
\text { campaigns to encourage } \\
\text { good health practices, } \\
\text { stay-at-home when ill, } \\
\text { etc. } \\
\text { Anticipate media and } \\
\text { public questions and } \\
\text { concerns on vaccine } \\
\text { issues }\end{array}$ & $\begin{array}{l}\text { Scenario D (high impact): } \\
\text { An influenza virus with } \\
\text { high transmissibility and } \\
\text { high virulence } \\
\text { - Anticipate that vaccine } \\
\text { issues (e.g., availability, } \\
\text { priority access, safety } \\
\text { and effectiveness) } \\
\text { will dominate public } \\
\text { communications } \\
\text { - Proactively monitor } \\
\text { and explain any } \\
\text { differences in public } \\
\text { health measures or } \\
\text { recommendations for } \\
\text { the use of vaccines and } \\
\text { antivirals (e.g., between } \\
\text { different } \\
\text { provinces/territories, } \\
\text { between Canada and } \\
\text { the United States) } \\
\text { Ensure consistent } \\
\text { reporting of case } \\
\text { counts, coordinated } \\
\text { between jurisdictions }\end{array}$ \\
\hline LOW & $\begin{array}{l}\text { Scenario A (low impact): } \\
\text { An influenza virus with low } \\
\text { transmissibility and low } \\
\text { virulence } \\
\text { - Plan for public } \\
\text { complacency (i.e., } \\
\text { people may not consider } \\
\text { themselves at risk) } \\
\text { - Provide appropriate } \\
\text { level of communications } \\
\text { to avoid information } \\
\text { saturation } \\
\text { - Anticipate that public risk } \\
\text { perception may focus on } \\
\text { the appropriateness of } \\
\text { the response efforts } \\
\text { - Be prepared for rapid } \\
\text { shifts in public perception } \\
\text { of risk (e.g., following a } \\
\text { fatality) }\end{array}$ & $\begin{array}{l}\text { Scenario C (moderate } \\
\text { impact): An influenza virus } \\
\text { with low transmissibility } \\
\text { and high virulence } \\
\text { - Anticipate that high } \\
\text { virulence (a virus } \\
\text { causing severe clinical } \\
\text { illness) will elevate } \\
\text { public concern } \\
\text { - Proactively } \\
\text { address concerns } \\
\text { through regular } \\
\text { communications using } \\
\text { multiple forms of } \\
\text { media } \\
\text { Target communications } \\
\text { to high-risk groups }\end{array}$ \\
\hline
\end{tabular}

of how these principles are applicable to other CPIP components include communicating decisions on early allocation of vaccines, prioritization of vaccines in the event of short supply, or communicating about public health measures such as social distancing or self-isolation when ill.

\section{Research needs}

Research related to risk communication, stakeholder management, behavioural science, modelling and tracking can play a key role in pandemic preparedness and response. There is an ongoing need to consider new communications tools, techniques and methodologies. While much of this research can be carried out during the interpandemic period, some can only be conducted during a pandemic (e.g., comparing vaccine uptake rates based on jurisdictional communication strategies). Given the potentially long intervals between events, proactive strategies need to be in place to capitalize on and to leverage these infrequent but invaluable learning opportunities. 


\section{Discussion}

A pandemic brings with it much uncertainty, which results in a high demand for information so people can make good decisions. Transparent, early and frequent communication with the public and stakeholders about what is known, and what remains unknown, is critical in reducing feelings of fear and anxiety while addressing misinformation and speculation-which remains a challenge given the rapid dissemination of information through electronic media.

Canada is diverse in terms of its size, geography, culture, languages and population needs. Specialized or tailored communications are required to be inclusive and account for traditional and alternative ways in which Canadians access information, while recognizing new technologies and trends in how Canadians are informed. These can be labour-intensive and challenging to prepare during a pandemic, so should be drafted ahead of time. A collaborative approach to developing, testing and evaluating messaging strategies would help inform the best approach during a pandemic.

The CPIP, with the Communications and Stakeholder Liaison Annex is intended to provide FPTs with planning guidance for addressing the communication challenges and planning advice during an influenza pandemic. The Annex is an evergreen document and, like the main body of the CPIP and the other technical annexes, will be reviewed and updated every five years.

\section{Conclusion}

The urgent and unpredictable nature of pandemics require a systematic approach to risk communications. In the early stages, evidence about the impact of a pandemic and the populations most at risk may be limited. The Communications and Stakeholder Liaison Annex has been designed to provide scalable communication strategies for varying pandemic wave activities in ways that will increase trust and self-empowerment among Canadians.

\section{Authors' statement}

Canadian Pandemic Influenza Preparedness Task Group (CPIPTG) Members: B Henry (Chair), C Alfieri, S Gantt, I Gemmill, T Hatchette, E Henry, B Schwartz

CPIP Secretariat: L Paddle, R Stirling, C Comeau

PHAC: P Salsbury, J Williams, S Smith, S Rempel

\section{Conflict of interest}

None.

\section{Acknowledgements}

Many thanks to Michel Amar who prepared the initial draft of this summary.

\section{Funding}

The work of the Canadian Pandemic Influenza Preparedness Task Group is supported by the Public Health Agency of Canada.

\section{References}

1. Pan Canadian Public Health Network. Canadian pandemic influenza preparedness: planning guidance for the health sector Ottawa (ON): Public Health Agency of Canada; 2018. Communications and Stakeholder Liaison Annex. https:// www.canada.ca/en/public-health/services/flu-influenza/ canadian-pandemic-influenza-preparedness-plannin g-guidance-health-sector/communications-stakeholde r-liaison-annex.html

2. Pan Canadian Public Health Network. Canadian pandemic influenza preparedness: planning guidance for the health sector. Ottawa (ON): Public Health Agency of Canada; 2015 https://www.canada.ca/en/public-health/services/flu-influenza/ canadian-pandemic-influenza-preparedness-planningguidance-health-sector.html

3. Henry B on behalf of the Canadian Pandemic Influenza Preparedness Task Group. Canada's Pandemic Influenza Preparedness: health sector planning guidance. Can Commun Dis Rep. 2018;44(1):6-9. http://dx.doi.org/10.14745/ccdr. v44i01a02

4. Henry B on behalf of the Canadian Pandemic Influenza Preparedness Task Group. Canada's Pandemic Influenza Preparedness: laboratory strategy. Can Commun Dis Rep. 2018;44(1):10-3. http://dx.doi.org/10.14745/ccdr.v44i01a03

5. Henry B on behalf of the Canadian Pandemic Influenza Preparedness Task Group. Canada's Pandemic Influenza Preparedness: surveillance strategy. Can Commun Dis Rep. 2018;44(1):14-7. http://dx.doi.org/10.14745/ccdr.v44i01a04

6. Henry B. Gadient S on behalf of the Canadian Pandemic Influenza Preparedness Task Group. Canada's pandemic vaccine strategy. Can Commun Dis Rep. 2017;43(7/8):164-7. http://dx.doi.org/10.14745/ccdr.v43i78a05

7. Health Canada. A framework for strategic risk communications within the context of Health Canada and the PHAC's integrated risk management. Ottawa (ON): Health Canada; 2006 [cited 2018 Mar 19]. https://www.canada.ca/en/healthcanada/corporate/about-health-canada/reports-publications/ strategic-risk-communications-framework-health-canadapublic-health-agency-canada.html 